\title{
Archival Afterlives: Life, Death, and Knowledge-Making in Early Modern British Scientific and Medical Archives. Edited by Vera Keller, Anna Marie Roos, and Elizabeth Yale. Leiden/Boston: Brill, 2018. 276 pp. Index. Hardcover. \$135.00.
}

Most extraordinary about this collection of essays documenting the life cycle of archives covering early modern scientific and medical thought, with the exception of one example of born-digital preservation, is that these archives survived at all. Essentially private archives until the papers contained in them had been obtained by institutions such as the Royal Society, the Ashmolean, and the Wellcome Library, the letters, studies, experiments, theories, speculations, and ephemera discussed in the essays underwent unpredictable transformational journeys. The history of these archives will cause archivists, librarians, scientists, and researchers reading the stories to gasp and to pine for lost items. The essays in Archival Afterlives: Life, Death, and Knowledge-Making in Early Modern British Scientific and Medical Archives present eight examples of scientific and medical collections that had been assembled; were transformed through publication, disaster, and handling; and eventually ended up as organized archives that have been preserved and passed on to become an important body of thought informing the modern scientific world. The eight essays, three written individually by the editors, constitute volume 23 of the publisher's Scientific and Learned Cultures and Their Institutions series. The volume is based on a 2015 conference sponsored by the Royal Society in England.

Seven of the eight essays illustrate the trajectories of seven different collections before and after the deaths of their creators. Despite the fact that the collections came from various sources and took diverse journeys from creation to eventual preservation-in some cases permanent loss - the essays address common questions and issues, as pointed out by the editors in the introduction. They query how and why the scientific records had been "attended to" and present the "efforts made to preserve, transmit, and make use" of the records, while illustrating how such efforts transformed the collections in some manner (p. 7). The book follows a chronological sequence, with each chapter covering a period of time, discussing, in particular, the papers of prominent naturalists Sir Francis Bacon, Sir Theodore de Mayerne, Samuel Hartlib, Martin Lister and Edward Lhuyd, Hans Sloane, and James Petiver. The final essay brings the reader into the twentieth and twenty-first centuries with a look at born-digital records related to the Human Genome Project collected by the Wellcome Library in London.

These naturalists expressed concerns about making sure future generations had access to the work they created during their professional lifetimes. However, as the essays make clear, early modern scientific thinkers did not have a way to secure their contributions by donating their papers to established archival institutions, libraries, or museums. They began to organize, create, and attempt to preserve their collections on their own. Francis Bacon's solution was to include in his will portions of his papers gifted to three individuals, who then went on to publish them. Unfortunately, printing the material in bound volumes often involved sacrificing the original documents, as they no longer seemed relevant or were destroyed in the print shops. Each essay highlights such challenges that occurred throughout a collection's life cycle. 
The stories vary in the details about the individuals involved and the journey and travails of the records. Martin Lister, the first thinker to study spiders and mollusks, involved his daughters-who had illustrated his work-with preserving his work as one of the earliest examples of scientific illustration. Samuel Hartlib inadvertently provided evidence and documentation of female naturalists active during the seventeenth century, in particular Princess Elisabeth of Bohemia (1618-1689), Bathsua Makin (c. 16001680), Dorothy Moore (c. 1612-1664), Katherine Jones, and Lady Ranelagh (16151691); great thinkers who feared their lives would have no lasting meaning because, as women, their work would not be preserved. The narratives have a common strain, documenting not only how the materials survived but also how random and unpredictable the development of archives can be, as well as how much can be lost along the way.

While the events related in most of the essays took place centuries ago, they reveal challenges that continue to plague archives today. The criteria used to determine which records are preserved and which are discoutarded can be subjective. As records are transposed to another form, the originals are in danger of being lost or destroyed, as was the case with Bacon's papers. By not consciously collecting the papers of underrepresented populations, such as female naturalists, the archival world is in danger of silencing valuable intellectual legacies. Records can reveal a number of trends, as is the case with Anna Marie Roos's examination of the collected ephemera of Martin Lister and Edward Lhuyd, expanding the meaning of archives beyond "paper and ink" (p. 150). In addition, any archivist would sympathize with Sir Hans Sloane working hard to make sense of the archival method of botanist James Petiver. Arnold Hunt, author of the essay on Petiver and Sloane, argues that Petiver would not have much of a scientific reputation without Sloane, who gave Petiver's archives an afterlife. Finally, the Wellcome Library's Collecting Genomics project exemplifies the modern challenges of collecting born-digital records related to the Human Genome Project (1960s-2000s).

As the afterword by Michael Hunter points out, the essays in the book address questions regarding how and why archives come into existence. As a whole, the volume provides a unique narrative that describes the evolution and transformation of archival collections created, developed, preserved, and transformed over time. The book illustrates the value of examining how papers important for historical and scientific research came to exist and survive. Value resides in examining how collections have been used and abused over time, and the role individuals and organizations like the Ashmolean at Oxford University, the Royal Society, and the Wellcome Library have played in ensuring contemporary access.

The essays demonstrate clearly that archives are not static entities. At the core, they are living, changing, evolving organisms. While some of the writing in Archival Afterlives is dense and bogged down in minutiae about the scientific records being preserved or lost, the essays demonstrate conscious efforts to create lasting collections-or archives. They illustrate purposeful efforts to publish, collect, and pass on collections for posterity, with the intention that they would be preserved and used again, long after their creators died. These are nail-biting, hair-raising, tragic, and triumphant stories about the creation, 
development, and afterlife of scientific archival collections, collected into one volume as encouragement for others to provide more.

Brian D. Fors

Curator

Waring Historical Library Medical University of South Carolina, Charleston 